\title{
Preface to special issue on "Minimally Invasive Surgery of the Thymus Gland"
}

\author{
Piergiorgio Solli \\ Department of Thoracic Surgery, Ospedale Maggiore Largo Nigrisoli, Bologna 2 - 40133, Italy.
}

Correspondence to: Dr. Piergiorgio Solli, Department of Thoracic Surgery, Ospedale Maggiore Largo Nigrisoli, Bologna 2 40133, Italy. E-mail: piergiorgio.solli@gmail.com

How to cite this article: Solli P. Preface to special issue on "Minimally Invasive Surgery of the Thymus Gland". Mini-invasive Surg 2019;3:28. http://dx.doi.org/10.20517/2574-1225.2019.37

Received: 23 Sep 2019 Accepted: 24 Sep 2019 Published: 30 Sep 2019

Science Editor: Giulio Belli Copy Editor: Jia-Jia Meng Production Editor: Jing Yu

I am thrilled to introduce this Minimally Invasive Surgery Journal special issue dedicated to surgery of the thymus gland.

The recently published international MGTX trial ${ }^{[1]}$ has confirmed the effectiveness of thymectomy in myasthenia gravis and although many unanswered questions still remain in the treatment of these patients, the positive results of the trial combined with a variety of available minimally invasive surgical techniques today available, could potentially lead to a much wider acceptance and utilization of thymectomy.

This issue is intended to offer an up-to date review of the several available technical surgical options and cover details of minimally invasive surgical approaches, presented by champions of those techniques, offering valuable lessons and practical tricks for experienced surgeons.

We are aware that the optimal surgical approach is only a part of the whole pathway for these patients, in fact only ongoing and future trials leaded by next generation of surgeons potentially will clarify the immunologic role of the thymus, the best medical strategy to myasthenic patients and eventually the best surgical approach to these patients. Nevertheless surgeons must be fully conscious of current concepts and focused on clear definitions that should be shared among our community, in order to effectively integrate our treatment in a multidisciplinary approach. 
Each article has been written by prominent respected physicians in the fields and this issue has been possible only thanks to the efforts of such eminent colleagues: to all of them I would like to express my personal words of gratitude.

\section{DECLARATIONS}

\section{Authors' contributions}

The author contributed solely to this preface.

\section{Availability of data and materials}

Not applicable.

\section{Financial support and sponsorship}

None.

\section{Conflicts of interest}

The author declared that there is no conflicts of interest.

\section{Ethical approval and consent to participate}

Not applicable.

\section{Consent for publication}

Not applicable.

\section{Copyright}

(c) The Author(s) 2019.

\section{REFERENCES}

1. Wolfe GI, Kaminski HJ, Aban IB, Minisman G, Kuo HC, et al. Randomized Trial of Thymectomy in Myasthenia Gravis. N Engl J Med 2016;375:511-522. 